\title{
Influence of Teacher-Student Matching on Knowledge Innovation of College Students
}

\author{
https://doi.org/10.3991/ijet.v16i01.19721 \\ Yuan Zhang \\ Jingdezhen Ceramic Institute, Jingdezhen, China \\ zhangyuanejci.edu.cn
}

\begin{abstract}
The relationship between teacher-student matching and knowledge innovation of college students is constrained by multiple factors. Considering the multiple constraints, this paper explores deep into the influence of teacher-student matching on knowledge innovation of college students. Firstly, the internal correlation between the two factors was identified through analysis. Next, the detailed contents of the two factors were examined, and used to set up an analysis model to improve knowledge innovation of college students based on teacher-student matching. Grey system theory and analytic hierarchy process (AHP) were implemented in the modeling process. Finally, several strategies were put forward to promote knowledge innovation among college students, from the perspective of teacher-student matching. The research results provide a strong support to knowledge innovation in colleges.
\end{abstract}

Keywords-Teacher-student matching, knowledge innovation, college students, evaluation model

\section{$1 \quad$ Introduction}

In the implementing process of the quality-oriented education model in higher education, more and more attention has been paid to the cultivation of college students' comprehensive quality and ability. Especially the knowledge innovation ability has gradually become a hot issue in higher education research due to the importance of knowledge in modern society and the increasing demand for innovative talents [1-3]. To effectively improve their own knowledge innovation ability, college students need to rely on various forces for guidance in knowledge innovation, because they're relatively weak in the aspects of professional knowledge level, scientific research innovation awareness and scientific research engineering practical experience. Whereas, teachers, with a good foundation in these aspects, are capable of guiding and promoting college students' knowledge innovation. Thus, a good teacher-student matching is conductive to improving the knowledge innovation ability of college students [4-6]. Some scholars have carried out related research and achieved certain results. For example, Roorda et al. [7] analysed the relationship between teachers and students in different subjects through survey research; Wu et al. [8] took university students in Taiwan as examples to analyse the influencing factors and hierarchical structure of 
university students' innovation ability; Pan [9] discussed the basic principles and related methods of college students' knowledge innovation ability evaluation; Fu et al. [10] proposed an extension comprehensive evaluation method for college students' innovation ability; Liu et al. [11] analysed the problem of teacher-student matching and gave a bilateral matching decision-making model for teacher-student perceived satisfaction; Wang [12] discussed the influence of the SECI model on college students' knowledge innovation and knowledge internalization, and put forward relevant suggestions for improving their knowledge innovation ability; Cheng et al. [13] probed into the impact of college campus culture on their knowledge innovation. However, it can be found that the current research focuses more on the partial links for improving the knowledge innovation ability of college students, failing to form a systematic theoretical system. In particular, the internal relationship between the teacher-student matching and knowledge innovation ability of college students should be further studied. Meanwhile, due to the existence of uncertain information, it's also necessary to explore how to quantify the influence of teacher-student matching on the knowledge innovation ability of college students. For this, the authors attempted to analyse the influence of teacher-student matching on the knowledge innovation of college students in this paper. The grey system theory [14-15] and AHP method [1617] was applied to build an analysis model for the influence of teacher-student matching on the knowledge innovation of college students.

This paper consists of 5 parts. The first part performs an overview and analysis of current research issues on the improvement effect of teacher-student matching on college students' knowledge innovation ability; the second part explores the relationship between teacher-student matching and college students' knowledge innovation; the third part establishes an analysis model for improving college students' knowledge innovation ability based on teacher-student matching; the fourth part discusses the related strategies; the last paper gives the research conclusion of this paper.

\section{The Relationship Between Teacher-Student Matching and College Students' Knowledge Innovation}

\subsection{Teacher-student matching broadens the perspective of college students' knowledge innovation}

Due to the rapid development of modern university education and continuous deepening of quality-oriented education, more emphasis has been placed on the absorption and digestion of new knowledge among college students, and especially the improvement of their comprehensive quality. To improve college students' comprehensive quality and ability, it involves knowledge transfer in different disciplines and majors, which is also the knowledge reserve for college students' knowledge innovation. For effectively absorbing and digesting the knowledge of different disciplines and majors, it is necessary to broaden the cognitive perspective of college students' knowledge innovation, and enable them to contact, understand and collect various types of professional knowledge. A good teacher-student matching relationship will 
help transfer the professional academic perspective of teachers to the knowledge innovation process of college students, and then broad the knowledge innovation perspective, so that college students can learn professional knowledge in more fields.

\subsection{Teacher-student matching deepens the content of college students' knowledge innovation}

From the perspective of the training objectives in higher education, the training of college students is a mode of cultivating advanced talents in a modern society. College students need to have both solid professional basic knowledge and good knowledge innovation capabilities, so that they can be more adapted to the development of modern society. In order to enhance college students' knowledge innovation ability, more attention should be paid to knowledge learning and innovation in the professional direction while extensively learning the knowledge of different subject areas, i.e., college students must possess both the broadened perspective and the deepened professional knowledge of knowledge innovation. A good teacher-student matching relationship is conducive to the deepening of professional knowledge in the process of knowledge innovation among college students. Teachers' knowledge, experience, and scientific research practical experience can all play a subtle role in promoting college students' professional knowledge learning. In such atmosphere, college students will gradually deepen their knowledge of professional knowledge, thereby promoting knowledge innovation.

\subsection{Teacher-student matching enriches practical approaches of college students' knowledge innovation}

College students' professional knowledge learning is divided into two types: Theoretical knowledge learning and practical knowledge learning. The former can be acquired through classroom learning, while the latter requires the use of various practical methods and forms. For example, college students can participate in teachers' scientific research projects and research teams to achieve professional knowledge learning and innovation; they can deepen their understanding of knowledge innovation in thematic activities such as science and technology competitions or innovation topics for college students; they can also enhance their personal knowledge innovation ability by participating in scientific research interest groups, scientific and technological societies, academic lectures, and academic salons, etc. It can be found that for any form of knowledge learning, it needs the guidance of professional teachers, especially for college students with weak professional knowledge, narrow professional perspective, and uneven professional level. Therefore, a good teacher-student matching relationship makes it easier to implement relevant knowledge innovation practical activities, and further enrich the practical approaches of college students' knowledge innovation. 


\subsection{Teacher-student matching enhances the application and transformation of college students' knowledge innovation}

The purpose of college students' knowledge innovation is to effectively transform professional knowledge into useful scientific research results for social development, and then achieve corresponding scientific research value and social application benefits. However, as a new force for knowledge innovation in the scientific research practice, college students cannot systematically and professionally master the application background, the development status and trend, the research hotspots, the technical bottleneck, the key scientific issues, and the technical implementation plan of knowledge innovation. In the application and transformation of college students' knowledge innovation achievements, It's necessary to rely on teachers' transformation platforms and systems of scientific research practice, and combine the teachers' scientific research direction to effectively integrate the results of college students' knowledge innovation with the industry-production-research mode, thereby enhancing the success rate and effectiveness in the application and transformation of knowledge innovation results. Therefore, a good teacher-student matching relationship will enhance the application and transformation of college students' knowledge innovation.

\subsection{Teacher-student matching provides the impetus for implementing college students' knowledge innovation}

College students' knowledge innovation is oriented. If it's oriented correctly, the implementation plan of knowledge innovation will be effective and often achieve a multiplier effect; otherwise, the implementation plan will be ineffective, failing to achieve the expected research results, or even obtaining wrong conclusions. Meanwhile, the knowledge innovation of college students needs to be carried out according to the interest of college students. If they are interested in the knowledge innovation, their enthusiasm for participation will be high, and they will be more delved into deep learning; on the contrary, the enthusiasm will be reduced, and they will often only have surface knowledge learning. Thus, orientation and interest are important factors for college students' knowledge innovation. On the one hand, a good teacher-student matching relationship can provide college students with academic guidance, and on the other hand, it can arouse their interest in scientific research and innovation. Thus, such a good relationship has become the impetus to implement the knowledge innovation of college students. Correspondingly, the improvement of college students' knowledge innovation ability is also conducive to the integration of the teacherstudent matching relationship. The two play a complementary role in promoting each other, forming a virtuous circle process. 


\section{Analysis Model for Improving College Students' Knowledge Innovation Ability Based on Teacher-Student Matching}

\subsection{The embodiment of college students' knowledge innovation behaviour}

In essence, college students' knowledge innovation means to learn knowledge based on their knowledge reserves using certain learning methods, then acquire new knowledge, and finally perform comprehension application and analysis. In the process of knowledge innovation, college students are subjected to a variety of factors. They need to not only have a certain basic professional knowledge, thinking ability, learning literacy, and learning methods, etc., but also develop a certain sense of innovation, a sound mental state, correct values and development concepts, and good moral conduct, etc., which all affect the implementation of college students' knowledge innovation behaviour. Therefore, the formation of college students' knowledge innovation behaviour needs to consider many aspects, including the knowledge innovation thinking, the knowledge innovation method, the knowledge innovation emotion, knowledge innovation consciousness, knowledge innovation personality, knowledge innovation plan, knowledge innovation activities, the knowledge innovation environment, and the knowledge innovation culture of college students, etc.

\subsection{The main content of teacher-student matching}

As above, the knowledge innovation of college students is constrained by a variety of influencing factors. To effectively deal with these influencing factors based on the teacher-student matching, it's necessary to explore the main content of the teacherstudent matching. The authors proposed the main contents from the perspective of cultivating college students' knowledge innovation as follows:

1) Matching between student's research interest and supervisor's research direction: From the perspective of college students' professional knowledge learning, they will first select teachers based on their personal research interests. Because the research direction of teachers is often not unique, there will be multiple subdivided research directions, which may be multi-field and interdisciplinary, and have a broader scope of scientific research knowledge innovation. Therefore, if the research interest of college students can match the research direction of the supervisors, it will help expand the cognitive perspective of college students' scientific research knowledge innovation, and also be more conducive to driving their scientific research interest in knowledge innovation, so that college students can be better integrated into the research team and research environment of the supervisor.

2) Matching of personality between students and supervisors: In the process of college students' knowledge innovation, the communication between college students and their supervisor plays a very important role. It's not only affected by the level of professional basic knowledge, but also closely related to the personality of students and supervisors. College students and supervisors may have different personalities, e.g., they are silent or talkative, prefer a quiet research environment or a 
lively discussion atmosphere, and like self-learning or teamwork; in case of problems, some are more eager or calm. From a psychological point of view, people with mismatched personalities tend to have some potential resistance emotions in the work process, making it difficult to implement the communication and cooperation between individuals smoothly. For this, more focus should be on the personality matching between college students and supervisors in order to effectively promote the communication and learning between college students and supervisors.

3) Matching between students' professional basis and the supervisor's guidance content: College students' professional courses generally include: The basic general knowledge, and the professional knowledge of the field, which two focus more on the cultivation of basic professional abilities or professional level. If college students want to expand their professional learning scope and strengthen the theoretical depth of learning content, they need to combine professional scientific practice projects or practical experience in the field; these two aspects are inseparable from the professional practice guidance content of the supervisor, especially the achievements accumulation of scientific research projects, which has a targeted promotion effect on the deepening and strengthening of the college students' professional basic ability. Therefore, an effective matching of the students' professional basis and the supervisor's guidance will have a positive effect on improving the knowledge innovation ability of college students.

4) Matching between students' learning styles and supervisor's teaching forms: From the process of college students receiving knowledge transfer, college students like different types of learning styles such as self-independent learning, professional knowledge learning with a strong theoretical basis, practical professional knowledge learning, exploratory knowledge learning, or heuristic knowledge learning style and so on. From the process of knowledge impartment, the supervisors also adopt different kinds of teaching forms such as scientific research projects, academic discussions, professional theoretical models, professional practical skills, one-to-one knowledge transfer with college students, and research groups etc. Thus, the learning styles of students and the teaching forms of supervisors are diverse. The teacher-student matching directly affects the depth of their knowledge exchange, and has a very critical influence on the formation of knowledge innovation among college students,

5) Matching between students' employment demands and supervisor's professional research level: Based on the knowledge innovation achievements of college students, a good knowledge innovation ability is often directly related to the employment demands of college students. If college students have strong knowledge innovation ability, under the premise of no lack of professional knowledge, it is generally easier to find a professional suited employment unit with a better development prospect, and to reflect the serviceability to the society. However, if they have poor knowledge innovation ability, and especially weak professional knowledge, the employment prospects are often not optimistic. So, it's important to expand the employment demands of college students and ensure their employment competitiveness. For this, a key factor is the professional research level of the supervisor. If 
the supervisors' professional research level has high social application value and strong sustainable development, their students will be easy to find suitable employment positions; otherwise, they may not find ideal ones. Therefore, a good matching between the employment demands of students and the professional research level of the supervisors can improve the knowledge innovation ability of college students.

\subsection{Evaluation system for the improvement of college students' knowledge innovation based on teacher-student matching}

In order to better reflect the hierarchical attributes of college students' knowledge innovation ability based on the teacher-student matching, the evaluation system was built in a hierarchical framework structure consisting of system layer, criterion layer and index layer. The system layer refers to the overall framework system S. The criterion layer includes the application ability of knowledge innovation R1, the learning ability of knowledge innovation R2, the collaboration ability R3 of knowledge innovation, the ability to capture knowledge innovation R4, the ability to share knowledge innovation R5, the social service ability of knowledge innovation R6, and the implementation effect of knowledge innovation R7 etc.

The index layer is to subdivide the evaluation indices under the above-mentioned criterion layer. In this study, R1 was characterized by the level of professional knowledge c11, the level of multidisciplinary knowledge integration $\mathrm{c} 12$, the level of innovative knowledge $\mathrm{c} 13$, and the ability to transform knowledge innovation c14. R2 was characterized by the thinking ability of knowledge learning c21, the self-learning ability c22, the ability to find problems c23, the ability to solve problems c24, practical ability c25, and the theory-practice integration ability c26. R3 was characterized by the planning ability for knowledge innovation $\mathrm{c} 31$, the ability to communicate and learn with instructors $\mathrm{c} 32$, the ability to communicate with team members $\mathrm{c} 33$, scientific exploration ability c34, the team-work ability c35, and the personal mental outlook and state c36. R4 was characterized by knowledge collection ability c41, knowledge sorting ability $\mathrm{c} 42$, knowledge extraction ability c43, and knowledge storage ability c44. R5 was characterized by the knowledge summary ability c51, the ability to communicate knowledge c52, the ability to transfer knowledge c53 (including the ability to apply or build a knowledge base or knowledge platform), the ability to integrate knowledge $\mathrm{c} 54$, and the ability to update knowledge c55. R6 was characterized by the industry-university-research integration c61, social satisfaction c62, supervisor satisfaction c63, and knowledge innovation results c64. R7 was characterized by participation in science and technology competitions c71, participation in scientific research projects $\mathrm{c} 72$, number of college students' scientific innovation projects $\mathrm{c} 73$, number of competition awards c74, scientific innovation project conclusions $\mathrm{c} 75$, published papers and patents $\mathrm{c76}$, and research achievement transformation c77. 


\subsection{Evaluation model for the improvement of college students' knowledge innovation ability based on teacher-student matching}

Different evaluation criteria and evaluation indices often have different degrees of importance. To build a more realistic and reliable evaluation model for the improvement of college students' knowledge innovation based on the teacher-student matching, AHP method [18-20] was used to obtain the weights at the criterion layer and index layer in this paper.

Evaluation experts were invited to score the evaluation indices (or evaluation criteria) of different layers using the 1-9 scale and make pairwise comparison. Then, the corresponding evaluation matrix A was obtained:

$$
\boldsymbol{A}=\left[a_{i j}\right]_{n \times n}
$$

where, aij is the ratio scale of the evaluation index ci (or evaluation criterion $\mathrm{Ri}$ ) relative to the evaluation index cj (or evaluation criterion $\mathrm{Rj}$ ). The larger the aij, the more important the former is relative to the latter, and it satisfies $1 \leq \mathrm{aij} \leq 9$, aij=1/aji, $1 \leq \mathrm{i}, \mathrm{j} \leq \mathrm{n}$.

The value RI corresponding to the random consistency index was selected through the number of evaluation indexes, to judge whether the judgment matrix A meets the consistency test requirements, namely:

$$
\left\{\begin{array}{l}
C I=\frac{\lambda_{\max }(A)-n}{n-1} \\
C R=C I / R I
\end{array}\right.
$$

where, $\lambda \max (\mathrm{A})$ is the largest characteristic root of the evaluation matrix $\mathrm{A}, \mathrm{CI}$ is the consistency index, and CR is the consistency ratio.

If $\mathrm{CR}<0.1$, it means that $\mathrm{A}$ meets the consistency test requirements; otherwise, an effective evaluation matrix needs to be re-obtained.

Therefore, the corresponding weight can be obtained as:

$$
w_{i}=\sqrt[n]{\prod_{j=1}^{n} a_{i j}} / \sum_{i=1}^{n} \sqrt[n]{\prod_{j=1}^{n} a_{i j}}
$$

Meanwhile, considering that different evaluation indices may have different dimensions, they need to be standardized. Assuming that the value of the evaluation object $\mathrm{k}$ about the evaluation index $\mathrm{ci}$ is $\mathrm{vk}(\mathrm{ci})$, if this evaluation index is a benefittype, its standardized value uk(ci) is given as:

$$
u_{k}\left(c_{i}\right)=\frac{v_{k}\left(c_{i}\right)-\min _{1 \leq k \leq m} v_{k}\left(c_{i}\right)}{\max _{1 \leq k \leq m} v_{k}\left(c_{i}\right)-\min _{1 \leq k \leq m} v_{k}\left(c_{i}\right)}
$$


If it's a cost index, its standardized value uk(ci) is given as:

$$
u_{k}\left(c_{i}\right)=\frac{\max _{1 \leq k \leq m} v_{k}\left(c_{i}\right)-v_{k}\left(c_{i}\right)}{\max _{1 \leq k \leq m} v_{k}\left(c_{i}\right)-\min _{1 \leq k \leq m} v_{k}\left(c_{i}\right)}
$$

Among them, $\mathrm{m}$ represents the number of evaluation objects.

It can be seen from the above that the standardized values all have a uniform metric, ranging between $0-1$. In order to better distinguish the hierarchical characteristics of college students' knowledge innovation ability improvement, the authors divided it into different evaluation levels. Assuming that there is a total of q evaluation levels for the improvement of the knowledge innovation ability, the classical domain corresponding to the h-th evaluation level of the evaluation index (ci) is uh(ci) $=[\mathrm{ua} \mathrm{h}$ (ci), $\mathrm{ub} \mathrm{h}(\mathrm{ci})]$. Based on the grey correlation theory [21-24], the grey correlation coefficient $\zeta \mathrm{k}-\mathrm{h}(\mathrm{ci})$ between the evaluation index ci and the h-th evaluation level for the evaluation object $\mathrm{k}$ is given as:

$$
\zeta_{k-h}\left(c_{i}\right)=\frac{\min _{1 \leq k \leq m} \min _{1 \leq i \leq n}\left(D\left(u_{h}\left(c_{i}\right) \rightarrow u_{k}\left(c_{i}\right)\right)\right)+\rho \max _{1 \leq k \leq m} \max _{1 \leq i \leq n}\left(D\left(u_{h}\left(c_{i}\right) \rightarrow u_{k}\left(c_{i}\right)\right)\right)}{D\left(u_{h}\left(c_{i}\right) \rightarrow u_{k}\left(c_{i}\right)\right)+\rho \max _{1 \leq k \leq m} \max _{1 \leq i \leq n}\left(D\left(u_{h}\left(c_{i}\right) \rightarrow u_{k}\left(c_{i}\right)\right)\right)}
$$

Among them, $\rho$ is the grey correlation distinguishing coefficient, and its value is generally 0.5 , satisfying:

$$
D\left(u_{h}\left(c_{i}\right) \rightarrow u_{k}\left(c_{i}\right)\right)=\frac{\left|u_{k}\left(c_{i}\right)-u_{h}^{a}\left(c_{i}\right)\right|+\left|u_{k}\left(c_{i}\right)-u_{h}^{b}\left(c_{i}\right)\right|}{2}
$$

Then, the weighted grey correlation degree $\tau \mathrm{k}$-h between the evaluation index ci and the $\mathrm{h}$-th evaluation level for the evaluation object $\mathrm{k}$ is shown as:

$$
\tau_{k-h}=\sum_{i=1}^{n}\left(w_{i} * \zeta_{k-h}\left(c_{i}\right)\right)
$$

If satisfying

$$
\tau_{k}=\tau_{k-s}=\max _{1 \leq h \leq q}\left\{\tau_{k-h}\right\}, 1 \leq s \leq q
$$

then it indicates that the current evaluation object belongs to the s-th evaluation level. If this evaluation level meets the requirements of the evaluation threshold, the teacher-student matching of the evaluation object has a significant effect on improving the knowledge innovation ability of college students; on the contrary, targeted improvement measures need to be taken. 


\section{Strategies for Improving the Knowledge Innovation Ability of College Students Based on Teacher-Student Matching}

In order to effectively improve the knowledge innovation ability of college students based on teacher-student matching, the authors proposed the following strategies:

\subsection{Creating a good atmosphere for teacher-student matching}

A good atmosphere is conductive to developing the teacher-student matching, i.e., the process of teacher-student matching will not be affected by many external factors, and it is also more convenient for teachers and students to show their personal character, scientific research interests, personality traits etc. In addition, it's easier for teachers and students to build personal feelings, which plays an important role in further promoting knowledge innovation ability. To create a good atmosphere and environment for matching between teachers and students, it's necessary to adhere to the principles of openness, fairness, and justness in the teacher-student matching process of matching between teachers and students, and create a good environment that can beneficially demonstrate personal characteristics.

\subsection{Enriching the communication ways and means for teacher-student matching}

In the early stage of matching between teachers and students, both often cannot fully understand each other. Especially now that the two-way selection between is implemented, students generally only learn about the teacher's research direction through personal profiles on the Internet, and teachers understand students' learning conditions from students' personal resumes. But this can only help to understand the apparent personal information, but not truly and effectively capture the in-depth content of both parties, such as the research interests of teachers or students, basic professional abilities of students, and research development prospects of teachers, etc., which are very important for the improvement of college students' knowledge innovation ability. To this end, diversified communication ways and means of teacherstudent matching should be adopted, e.g., opening summer camps, providing academic lectures, or building a digital platform and system.

\subsection{Improving the rules and regulations for teacher-student matching}

The rules and regulations are important guarantees for the orderly development of teacher-student matching. In the process of teacher-student matching, both teachers and students should strictly abide by the relevant rules and regulations. The rules and regulations for teacher-student matching need to be characterized by goal-orientation, pertinence, comprehensiveness, objectivity, and development, to effectively promote 
the college students' knowledge innovation ability based on the teacher-student matching.

\subsection{Establishing an effective teacher-student matching mechanism}

An effective teacher-student matching mechanism refers to relevant measure that can ensure the scientificity and rationality of teacher-student matching, and make teachers and students satisfied with each other. These measures must have a certain degree of operability and sustainable development, namely incentive, punitive and management measures for teacher-student matching, which are mainly to examine the performance analysis of teacher-student matching on the improvement of college students' knowledge innovation ability. If teacher-student matching is beneficial to the improvement of college students' knowledge innovation ability, relevant incentives or rewards will be provided; if not, a warning or punishment will be given to relevant responsible entities. To ensure the effective implementation of such incentive and punitive measures, corresponding management measures are required.

\subsection{Forming a publicity and feedback model for teacher-student matching}

Through the performance analysis for the improvement of college students' knowledge innovation ability based on teacher-student matching; it can be found that there are some representative application cases. For these typical cases, extensive publicity needs to be carried out, to make teachers and students have a broader and deeper understanding of the improvement effect of teacher-student matching on college students' knowledge innovation ability. For some application cases with unsatisfactory or poor results, effective supervision is required, and the existing problems and weak links should be fed back to the responsible subject so that they can make targeted improvements in future. This shall further form a virtuous cycle, and effectively promote college students' knowledge innovation ability.

\section{Conclusion}

This paper analyses the internal correlation between teacher-student matching and college students' knowledge innovation, and concludes that a good teacher-student matching will provide important support for the improvement of college students' knowledge innovation. Besides, it embodies the essence of college students' knowledge innovation and content of the teacher-student matching, and establishes a new evaluation system for the improvement of college students' knowledge innovation ability based on teacher-student matching. Next, based on the grey system theory and AHP method, an evaluation model was built to systematically and quantitively analyse the improvement of college students' knowledge innovation. Finally, some relevant strategies were proposed from the perspective of teacher-student matching, which has a good guiding significance for effectively improving the knowledge innovation ability of college students. 


\section{References}

[1] Pugacheva, N., Kirillova, T., Kirillova, O., Lunev, A., Pavlova, O. (2019). Forming the basic mathematical knowledge among technical students, International Journal of Emerging Technologies in Learning, 15(3): 34-50. https://doi.org/10.3991/ijet.v15i03.116 $\underline{86}$

[2] Elas, N.I.B., Majid, F.B.A., Narasuman, S.A. (2019). Development of Technological Pedagogical Content Knowledge (TPACK) for English teachers: The validity and reliability, International Journal of Emerging Technologies in Learning, 14(20): 18-33. https://doi.org/10.3991/ijet.v14i20.11456

[3] Liu, R.J., Zhai, K., Wu, J.S., Zhu, L.Q. (2012). Educational methods, practice and experience of cultivating students' knowledge innovation ability. Higher Agricultural Education, 11(11): 70-74. https://doi.org/10.13839/j.cnki.hae.2012.11.017.

[4] Dong, Y., Wang, M. (2016). Research on the formation mechanism of teacher student matching teaching style. Theory and Practice of Contemporary Education, 8(11): 45-48. https://doi.org/10.13582/j.cnki.1674-5884.2016.11.015.

[5] Sang, D.M. (2019). Research on the selection and determination of graduate tutors. Education Modernization, 6(78): 107-108. https://doi.org/10.16541/j.cnki.2095-8420.2019. $\underline{78.046}$.

[6] Zhang, Y.B. (2015). Mechanism of Innovative Learning in Universities: A Case Study. Journal of Yangzhou University (Higher Education Study Edition), 19(4): 78-82. https://doi.org/10.19411/j.cnki.1007-8606.2015.04.019.

[7] Roorda, D.L., Jorgensen, T.D., Koomen, H.M. (2019). Different teachers, different relationships? Student-teacher relationships and engagement in secondary education. Learning and Individual Differences, 75: 101761. https://doi.org/10.1016/j.lindif.2019.101 $\underline{761}$

[8] Wu, M., Siswanto, I., Ko, C. (2017). The influential factors and hierarchical structure of college students' creative capabilities - An empirical study in Taiwan. Thinking Skills and Creativity, 26: 176-185. https://doi.org/10.1016/j.tsc.2017.10.006.

[9] Pan, Y.P. (2012). Research of theory and method about the evaluation of college students' innovation ability. Journal of Xinyang Agricultural College, 22(3): 139-141. https://doi.org/10.16593/i.cnki.41-1433/s.2012.04.033.

[10] Fu, D., He. Z.F., Ke, Y. (2015). Application of Extension Comprehensive Evaluation Method in Assessment of College Students Innovation Ability. Rducatton Rrsrarch Monthlv, 2015(8): 47-52. https://doi.org/10.16477/j.cnki.issn1674-2311.2015.08.007.

[11] Liu, J., Yang, Q., Zhou, Y.W., Cao, C.J. (2020). A Two-sided Matching Decision Model Considering Perception Satisfaction of Postgraduates and Supervisors. Operations Research and Management Science, 29(3): 16-26.

[12] Wang, L. (2016). The influence and Enlightenment of SECI model on College Students' knowledge innovation and knowledge internalization. Western China Quality Education, 2(19): 50-51. https://doi.org/10.16681/j.cnki.wcqe.201619027.

[13] Cheng, G., Wu, D.M., Xu, X.T. (2018). The Influence of Campus Culture on University Students' Knowledge Innovation. Information Research, 2018(7): 1-6. http://dx.doi.org /10.3969/j.issn.1005-8095.2018.07.001.

[14] Zhao, K., Wang, D., Wang, Y. (2019). A face recognition algorithm based on optimal feature selection. Revue d'Intelligence Artificielle, 33(2): 105-109. https://doi.org/10.18 280/ria.330204 
[15] Shang, H. (2020). Model and algorithms of enterprise informatization software selection based on grey relational analysis. Ingénierie des Systèmes d'Information, 25(1): 107-112. https://doi.org/10.18280/isi.250114

[16] Akbulut, A., Ozcevik, O., Carton, L. (2018). Evaluating suitability of a GIS-AHP combined method for sustainable urban and environmental planning in Beykoz district, Istanbul. International Journal of Sustainable Development and Planning, 13(8): 11031115. https://doi.org/10.2495/SDP-V13-N8-1103-1115

[17] Ghimire, L.P., Kim, Y. (2018). An analysis on barriers to renewable energy development in the context of Nepal using AHP. Renewable energy, 129: 446-456. https://doi.org/10.10 16/j.renene.2018.06.011.

[18] Neissi, L., Albaji, M., Nasab, S.B. (2020). Combination of GIS and AHP for site selection of pressurized irrigation systems in the Izeh plain, Iran. Agricultural Water Management, 231: 106004. https://doi.org/10.1016/j.agwat.2020.106004.

[19] Pilevar, A.R., Matinfar, H.R., Sohrabi, A., Sarmadian, F. (2020). Integrated fuzzy, AHP and GIS techniques for land suitability assessment in semi-arid regions for wheat and maize farming. Ecological Indicators, 110: 105887. https://doi.org/10.1016/j.ecolind.2019. 105887.

[20] Azimifard, A., Moosavirad, S.H., Ariafar, S. (2018). Selecting sustainable supplier countries for Iran's steel industry at three levels by using AHP and TOPSIS methods. Resources Policy, 57: 30-44. https://doi.org/10.1016/j.resourpol.2018.01.002.

[21] Das, R., Ball, A.K., Roy, S.S. (2018). Optimization of E-jet Based Micro Manufacturing Process Using Grey Relation Analysis. Materials Today: Proceedings, 5(1): 200-206. https ://doi.org/10.1016/j.matpr.2017.11.072

[22] Sarraf, F., Nejad, S.H. (2020). Improving performance evaluation based on balanced scorecard with grey relational analysis and data envelopment analysis approaches: Case study in water and wastewater companies. Evaluation and Program Planning, 79: 101762. https://doi.org/10.1016/j.evalprogplan.2019.101762.

[23] Acır, A., Canlı, M.E., Ata, İ., Çakıroğlu, R. (2017). Parametric optimization of energy and exergy analyses of a novel solar air heater with grey relational analysis. Applied Thermal Engineering, 122: 330-338. https://doi.org/10.1016/j.applthermaleng.2017.05.018.

[24] Hubeatir, K.A. (2020). Laser transmission welding of PMMA using IR semiconductor laser complemented by the Taguchi method and grey relational analysis. Materials Today: Proceedings, 20: 466-473. https://doi.org/10.1016/j.matpr.2019.09.167.

\section{$7 \quad$ Author}

Yuan Zhang is a lecturer of College English department of Jingdezhen Ceramic Institute. She received the master's degree of English-Chinese Translation from Xi'an International Studies University in 2014, and Bachelor's degree of English Literature and Linguistics from Jilin University in 2006. She focuses on teaching reform and teaching-learning result.

Article submitted 2020-11-04. Resubmitted 2020-12-18. Final acceptance 2020-12-19. Final version published as submitted by the authors. 